OPEN ACCESS

Edited by:

Hiroyuki Okuno,

Kagoshima University, Japan

Reviewed by:

Ramesh Kandimalla,

Texas Tech University Health

Sciences Center, United States

Xudong Huang,

Massachusetts General Hospital and Harvard Medical School,

United States

*Correspondence:

Wenjun Tan

tanwenjun@cse.neu.edu.cn

Received: 16 May 2019 Accepted: 01 October 2019 Published: 18 October 2019

Citation:

Liu Y, Tan W, Chen C, Liu C, Yang J and Zhang $Y$ (2019) A Review of the Application of Virtual Reality

Technology in the Diagnosis and

Treatment of Cognitive Impairment.

Front. Aging Neurosci. 11:280. doi: 10.3389/fnagi.2019.00280

\section{A Review of the Application of Virtual Reality Technology in the Diagnosis and Treatment of Cognitive Impairment}

\author{
Yao Liu ${ }^{1}$, Wenjun Tan ${ }^{1,2 *}$, Chao Chen ${ }^{3}$, Chunyan Liu ${ }^{4}$, Jinzhu Yang ${ }^{1}$ and Yanchun Zhang ${ }^{2,5}$ \\ ${ }^{1}$ Key Laboratory of Intelligent Computing in Medical Image, Ministry of Education, Northeastern University, Shenyang, China, \\ ${ }^{2}$ Cyberspace Institute of Advanced Technology, Guangzhou University, Guangzhou, China, ${ }^{3}$ Key Laboratory of Complex \\ System Control Theory and Application, Tianjin University of Technology, Tianjin, China, ${ }^{4}$ Department of Neurology, Xuanwu \\ Hospital, Capital Medical University, Beijing, China, ${ }^{5}$ Centre for Applied Informatics, College of Engineering and Science, \\ Victoria University, Melbourne, VIC, Australia
}

At present, with the development of an aging society and an increase in the number of elderly people, in order to ensure the ability and enthusiasm of the elderly to live independently, it is necessary to ensure that they can understand the world in a normal way. More and more elderly people have cognitive impairment, and virtual reality (VR) technology is more effective in cognitive diagnosis and treatment than traditional methods. This review article describes some studies on cognitive diagnosis and training for the elderly, and puts forward some suggestions for current studies, in the hopes that VR technology can be better applied to cognitive diagnosis and training.

Keywords: virtual reality, cognitive impairment, cognitive training, cognitive rehabilitation, Alzheimer's disease

\section{INTRODUCTION}

\section{Cognitive Impairment}

Cognitive processes are defined by a neural process that allows us to interact with complex environments in a goal-oriented manner. It is a multifaceted process that includes attention, memory, language, emotion, etc. When multitasking is done at the same time, the normal brain can correctly process the information obtained from the complex environment and avoid interference with useless information. When the brain is in a normal state, this process can proceed smoothly, but if the brain produces lesions, this cognitive process will fail, leading to memory impairment, learning disabilities, attention deficits, and aphasia (Anguera et al., 2013).

Moreover, with the aging of today's society, age is the most common cause of cognitive impairment in an increasing number of people entering old age (Tarnanas et al., 2014a,b), which has led to an increasing number of cognitive impairments in the elderly. Progressive decline in cognitive function leads to neuropsychological disorders such as Alzheimer's disease (AD), including amnesic cognitive impairment in high-risk populations of AD (Tarnanas et al., 2015). Older people with cognitive impairments may not be able to take care of their own lives. They may lose their memory, the ability to navigate through spaces, and the ability to communicate with others. They may not be able to participate in daily activities such as boiling water, cooking, driving, and so on. Cognitive impairment in the family can be a major burden on the family. Children may not have the time and energy to take care of the sick elderly, and the elderly often need professional caregivers to look after 
them. For the elderly, damage to the brain's nervous system, which causes cognitive impairment, may even be irreversible, meaning the disease is incurable. For a country, a growing number of elderly people's cognitive aging will lead to more social problems.

However, if the disease can be diagnosed in the early stages of cognitive training and recovery, it can be gradually recovered. But it is difficult to use neuropsychological methods for diagnosis, and there is no effective method of cognitive training. In this context, the introduction to virtual reality (VR) technology provides a very viable way to explore more cognitive diagnosis and recovery programs to prevent and delay cognitive aging, to ensure the normal life of the elderly, and to maintain the enthusiasm and vitality of independent life for the elderly (Klimova, 2016).

\section{Virtual Reality Technology}

In recent years, VR technology has developed rapidly, and it is one of the most promising and challenging technologies in computer graphics. VR is a technology that uses computer technology and interactive devices (such as head mounted displays, handles, gloves, etc.) to artificially create an environment close to the real world, allowing one or more people to interact with the virtual environment and its $3 \mathrm{D}$ entities (Gatica-Rojas and Méndez-Rebolledo, 2014; Tan et al., 2019a,b).

At present, VR has been proposed to treat some neuropsychological diseases such as anxiety and fear. VR technology can intuitively provide patients with an almost real environment; patients can be placed at the center of things and get better treatment results. At the same time, VR can also be used for surgical training to provide doctors with a recyclable and ecologically efficient way to gain more training experience. VR can also be used for other medical purposes such as post-stroke intervention and treatment.

In VR, several sensory perceptions are mainly used, including vision, touch, and kinematics. In the process of interaction between human and virtual environment, the transmission of information must be real-time, and it can make corresponding responses to human actions in time so that people can operate it fluidly. The use of VR in the diagnosis and treatment of cognitive impairment can provide a fully controlled experimental environment for timely observation of memory, emotion, perception, motion control, and other aspects of the user (Tarnanas et al., 2014a,b).

The environment provided by VR for the diagnosis or treatment of cognitive impairment can be divided into three levels of systemic immersion: non-immersion, semi-immersion, and full immersion. The difference between these three levels is the reality of the reality simulation. The better the immersion, the more realistic the virtual environment is, the more realistic the participants will be (García-Betances et al., 2015). Different experimental tasks may require varying degrees of immersion, and non-immersion limits the risks of simulation disease and is more portable than a $3 \mathrm{D}$ environment. But a higher level of immersion would provide a more realistic environmental effect. VR technology has obvious advantages in the diagnosis and treatment of cognitive impairment. First, it can provide an ecologically efficient way to diagnose and treat patients (Allain et al., 2014). VR can measure a subject's behavior in an ecologically efficient environment and place the subject in a virtual environment to provide the physician with a judgment of the condition (Rizzo et al., 2004). Second, the combination of VR and neuropsychology as a non-pharmacological approach can be performed before symptoms occur (where symptoms mean the conditions that occur in patients with cognitive impairment, such as forgetting, being unable to move at will, etc.), and this approach is non-invasive. Third, experimenting in a virtual environment can avoid the dangers caused by improper patient operation and provide a safer environment. When participants enter a virtual environment, however, it can cause discomfort, such as dizziness. But it is undeniable that it is a very effective method for cognitive diagnosis and treatment.

\section{COGNITIVE DIAGNOSIS AND TREATMENT WITH VR}

In this section, some recent studies on cognitive diagnosis and treatment using VR technology are briefly classified according to their research objectives, and the main research methods and expected results are summarized. Table 1 summarizes the main features of these articles. The research objectives of these articles are mainly divided into two aspects: the first is to evaluate and diagnose cognition, and the second is to train and treat cognition.

\section{Research on Cognitive Diagnosis}

Godehard Weniger's studies assessed self-centered and heteroego-centered memory in individuals with amnesic mild cognitive impairment (aMCI) through VR. A total of 29 patients with aMCI and 29 healthy controls were enrolled in the study. In this experiment, a virtual maze of self-centered memories was set up, and a virtual park of hetero-ego-centered memories was set up. This study demonstrates the feasibility of VR techniques to study spatial memory deficits in aMCI patients, and the future direction of its use is to be able to predict the transition from MCI to AD and from normal to MCI (Weniger et al., 2011).

Plancher et al. (2012) used VR in aMCI and AD to study the characteristics of episodic memory. A total of 21 healthy elderly people, 15 aMCI patients, and $15 \mathrm{AD}$ patients were selected to complete the task. Two virtual environments were designed: one for participants to act as drivers of virtual vehicles and the other for participants to act as passengers of virtual vehicles. The patient's recall and identification of central information (i.e., environmental elements), contextual information (i.e., time, egocentric and distribution center spatial information), and the overall combined qualities were assessed. In this study, the performance of these participants was found to be consistent with atrophy of the hippocampus. The performance of $\mathrm{AD}$ patients was the worst. Spatial distribution memory assessment was particularly useful for distinguishing between aMCI patients and healthy older adults. Cognitive differences between the three groups can provide effective recommendations for the early diagnosis and 
TABLE 1 | Recent virtual reality (VR)-based studies on cognitive diagnosis and treatment.

\begin{tabular}{|c|c|c|c|c|}
\hline First author & Participants & Virtual environment & Target & Results \\
\hline Godehard Weniger & $29 \mathrm{aMCl}, 29$ healthy controls & VR-Maze, VR-Park & $\begin{array}{l}\text { Patients with aMCI were } \\
\text { evaluated for self-centered and } \\
\text { hetero-ego-centered memory }\end{array}$ & $\begin{array}{l}\text { VR technique can indicate } \\
\text { spatial memory impairment in } \\
\text { aMCl patients }\end{array}$ \\
\hline G.Plancher & 29 aMCl, 29 healthy controls & Virtual automobile environment & $\begin{array}{l}\text { Use VR to describe the } \\
\text { characteristics of episodic } \\
\text { memory }\end{array}$ & $\begin{array}{l}\text { Virtual environment can be } \\
\text { used as a tool to characterize } \\
\text { episodic memory }\end{array}$ \\
\hline Francesca Morganti & 26 AD, 26 healthy controls & VR-Maze, VR-Road Map & $\begin{array}{l}\text { Using VR technology, we study } \\
\text { the transition from heterosexual } \\
\text { space to self-space in early AD }\end{array}$ & $\begin{array}{l}\text { In the early stages of } A D \text {, there } \\
\text { were shortcomings in the } \\
\text { planning of space missions }\end{array}$ \\
\hline Silvia Serino & $\begin{array}{l}15 \text { healthy controls, } 15 \mathrm{aMCl} \text {, } \\
15 \text { early-AD }\end{array}$ & Virtual room & $\begin{array}{l}\text { VR was used to detect the } \\
\text { defects of egocentric and } \\
\text { hetero-centric in early AD }\end{array}$ & $\begin{array}{l}\text { AMCI patients and AD patients } \\
\text { have defects in different } \\
\text { aspects }\end{array}$ \\
\hline Glen M. Doniger & $\begin{array}{l}125 \text { adults with a family history } \\
\text { of } A D\end{array}$ & Virtual supermarket & $\begin{array}{l}\text { Cognitive motor training based } \\
\text { on VR was given to } \\
\text { middle-aged people with high } \\
\text { risk of Alzheimer's disease }\end{array}$ & $\begin{array}{l}\text { Effectively improve } \\
\text { cognitive ability }\end{array}$ \\
\hline Déborah A. Foloppe & $1 \mathrm{AD}$ & Virtual kitchen & $\begin{array}{l}\text { Enhance the autonomy of AD } \\
\text { patients in cooking activities }\end{array}$ & $\begin{array}{l}\text { Patients regain the ability } \\
\text { to cook }\end{array}$ \\
\hline Moffat Mathews & 15 stroke patients & - & $\begin{array}{l}\text { Recovery of prospective } \\
\text { memory in stroke patients }\end{array}$ & $\begin{array}{l}\text { Participants' prospective } \\
\text { memory improved well }\end{array}$ \\
\hline Paul J.f. White & 1 early-AD & $\begin{array}{l}\text { Virtual buildings without } \\
\text { landmarks }\end{array}$ & $\begin{array}{l}\text { Neurocognitive therapy was } \\
\text { performed in AD patients using } \\
\text { VR navigation environment }\end{array}$ & Enhanced spatial cognition \\
\hline Silvia Serino & 20 AD, 8 healthy controls & Virtual city & $\begin{array}{l}\text { Enhancing mental frame } \\
\text { synchronization in AD patients }\end{array}$ & Effective improvement \\
\hline
\end{tabular}

rehabilitation of pathological aging, and they prove that the virtual environment can be used as a tool to characterize episodic memory.

Morganti et al. (2013) published a article in 2013 that used VR technology to study the early transition of $\mathrm{AD}$ from a heterosexual space to its own spatial capabilities. In the study, 26 early AD patients and 26 healthy seniors were assigned to two virtual environment tasks: a VR-Maze and a VR-Road Map, both of which provide different path finding processes. This study shows that in the early stage of $\mathrm{AD}$, the planning of spatial tasks is insufficient, and, in the task of transforming heterosexual spatial memory into an effective path of path finding, the ability of spatial memory is insufficient.

In Serino et al.'s (2015) study, VR was used to detect the egocentric and hetero-centric defects of early AD. The study involved 15 patients with early AD, 15 aMCI patients, and 15 cognitively healthy subjects completing two tasks. In the first task, participants needed to indicate the location of the objects they remember on the real map, while in the second task they were invited to retrieve their locations from different starting points in the empty version of the same virtual room. Comparing the performances of the three groups of participants showed that aMCI patients had deficiencies in storing hetero-centric independent representational memories and $\mathrm{AD}$ patients had deficiencies in storing hetero-centric independent representational memories and their synchrony. This may reflect the selective flaws in spatial organization, and these findings provide a preliminary understanding of the cognitive basis of amnesic damage.

\section{The Goal Is to Study Cognitive and Training Therapy}

Doniger et al.'s (2018) study of VR-based cognitive motor training for middle-aged people at high risk of $\mathrm{AD}$ used VR technology to intervene in middle-aged people with high risk of $\mathrm{AD}$ in a non-pharmaceutical manner, offering effective prevention possibilities for middle-aged asymptomatic but high-risk people. In this study, a total of 125 middle-aged people aged 40-65 years with a family history of $\mathrm{AD}$ participated in the study and were randomly divided into four groups. The first group performed cognitive stimulation on a treadmill, the second group performed the same task without a treadmill, the third group performed non-specific cognitive stimulation on a treadmill, and the fourth group did not receive training as a control group. After 3 months of training, they conducted a cognitive assessment and concluded that cognitive training can effectively improve cognitive ability.

Foloppe et al. (2018) used a case study to discuss how VR-based cognitive training can enhance the autonomy of $\mathrm{AD}$ patients in cooking activities. The study evaluated a 79-yearsold $\mathrm{AD}$ patient who was trained in four cooking tasks in a non-immersive manner, and it showed that VR restored the patient's ability to perform cooking activities.

Mathews et al. (2016) used a virtual environment to test prospective memory (PM) recovery in stroke patients. Using non-immersive VR techniques, the study of 15 stroke patients showed that participants' PM was significantly improved by VR-based cognitive training. 
White and Moussavi (2016) used a VR navigation (VRN) environment for neurocognitive therapy in $\mathrm{AD}$ patients. The study involved a 74-year-old man who was in the early stages of $\mathrm{AD}$ and was asked to perform navigation tasks in a virtual environment. The results showed that the cognitive ability of the participants was enhanced by the cognitive rehabilitation task.

Serino et al. (2017) conducted a new VR-based training approach to enhance psycho-frame synchronization of $\mathrm{AD}$ patients. "Psychological frame synchronization" refers to the specific cognitive process of transition between egocentric and hetero-egocentric. The project recruited eight healthy elderly people and $20 \mathrm{AD}$ patients, of whom 10 were healthy. Ten $\mathrm{AD}$ patients performed navigation tasks in a virtual environment, and the other $10 \mathrm{AD}$ patients served as controls. The results showed that the spatial memory of $\mathrm{AD}$ patients and healthy people were effectively improved.

\section{CONCLUSION}

VR technology is a very effective tool for cognitive assessment and recovery. It enables researchers and doctors to monitor patients' responses in real time, which traditional methods may not have permitted them to do. The interactivity of VR allows participants to use multiple senses for feedback to get more details. VR works in an ecologically efficient way and pages are safer. There is still room for improvement in the study of VR for cognitive diagnosis and recovery. In most studies, the number of participants was insufficient, which led to more uncontrollable factors in the experiment. Therefore, in an experiment, we

\section{REFERENCES}

Allain, P., Foloppe, D. A., Besnard, J., Yamaguchi, T., Etcharry-Bouyx, F., Le Gall, D., et al. (2014). Detecting everyday action deficits in Alzheimer's disease using a nonimmersive virtual reality kitchen. J. Int. Neuropsychol. Soc. 20, 468-477. doi: 10.1017/S1355617714000344

Anguera, J. A., Boccanfuso, J., Rintoul, J. L., Al-Hashimi, O., and Gazzaley, A. (2013). Video game training enhances cognitive control in older adults. Nature 501, 97-101. doi: 10.1038/nature 12486

Doniger, G. M., Beeri, M. S., Bahar-Fuchs, A., Gottlieb, A., Tkachov, A., Kenan, H., et al. (2018). Virtual reality-based cognitive-motor training for middle-aged adults at high Alzheimer disease risk: a randomized controlled trial. Alzheimers. Dement. 4, 118-129. doi: 10.1016/j.trci.2018. 02.005

Foloppe, D. A., Richard, P., Yamaguchi, T., Etcharry-Bouyx, F., and Allain, P. (2018). The potential of virtual reality-based training to enhance the functional autonomy of Alzheimer's disease patients in cooking activities: a single case study. Neuropsychol. Rehabil. 28, 709-733. doi: 10.1080/09602011.2015. 1094394

García-Betances, R. I., Arredondo Waldmeyer, M. T., Fico, G., and CabreraUmpiérrez, M. F. (2015). Corrigendum: a succinct overview of virtual reality technology use in Alzheimer's disease. Front. Aging Neurosci. 7:235. doi: 10.3389/fnagi.2015.00235

Gatica-Rojas, V., and Méndez-Rebolledo, G. (2014). Virtual reality interface devices in the reorganization of neural networks in the brain of patients with neurological diseases. Neural Regen. Res. 9, 888-896. doi: 10.4103/1673-5374. 131612

Klimova, B. (2016). Computer-based cognitive training in aging. Front. Aging Neurosci. 8:313. doi: 10.3389/fnagi.2016.00313

Mathews, M., Mitrovic, A., Ohlsson, S., Holland, J., and McKinley, A. (2016). A virtual reality environment for rehabilitation of prospective memory in need to recruit as many participants as possible to improve the participation of patients, better understand their needs, coordinate different services, and access participants in a longterm, timely manner to obtain experiments. Although much research has been done, more research is needed on the scale of its use in patients.

\section{AUTHOR CONTRIBUTIONS}

YL wrote this article. WT presented the major idea of this article. CC collected the research articles. CL presented the method of diagnosis and treatment of cognitive impairment in hospital. JY corrected the article. YZ presented the VR method in the diagnosis and treatment of cognitive impairment.

\section{FUNDING}

This work was supported by the Fundamental Research Fund of Central University (N181602014), the National Key Research and Development Program of China (2018YFC1314501), and the National Natural Science Foundation of China $(61971118,61806146)$.

\section{ACKNOWLEDGMENTS}

We would like to thank the editors and reviewers for their valuable suggestions that have helped improve the quality of the article.

stroke patients. Procedia Comput. Sci. 96, 7-15. doi: 10.1016/j.procs.2016 08.081

Morganti, F., Stefanini, S., and Riva, G. (2013). From allo- to egocentric spatial ability in early Alzheimer's disease: a study with virtual reality spatial tasks. Cogn. Neurosci. 4, 171-180. doi: 10.1080/17588928.2013.854762

Plancher, G., Tirard, A., Gyselinck, V., Nicolas, S., and Piolino, P. (2012). Using virtual reality to characterize episodic memory profiles in amnesic mild cognitive impairment and Alzheimer disease: influence of active and passive encoding. Neuropsychologia 50, 592-602. doi: 10.1016/j.neuropsychologia. 2011.12.013

Rizzo, A. A., Schultheis, M. T., Kerns, K., and Mateer, C. (2004). Analysis of assets for virtual reality applications in neuropsychology. Neuropsychol. Rehabil. 14, 207-239. doi: 10.1080/09602010343000183

Serino, S., Morganti, F., Di Stefano, F., and Riva, G. (2015). Detecting early egocentric and allocentric impairments deficits in Alzheimer's disease: an experimental study with virtual reality. Front. Aging Neurosci. 7:88. doi: 10.3389/fnagi.2015.00088

Serino, S., Pedroli, E., Tuena, C., De Leo, G., Stramba-Badiale, M., Goulene, K., et al. (2017). A novel virtual reality-based training protocol for the enhancement of the "mental frame syncing" in individuals with Alzheimer's disease: a development-of-concept trial. Front. Aging Neurosci. 9:240. doi: 10.3389/fnagi.2017.00240

Tan, W. J., Kang, Y. A., Dong, Z. W., Chen, C., Yin, X., Su, Y., et al. (2019a). An approach to extraction midsagittal plane of skull from brain CT images for oral and maxillofacial surgery. IEEE Access 7, 118203-118217. doi: 10.1109/access. 2019.2920862

Tan, W. J., Yuan, Y., Chen, A., Mao, L., Ke, Y., and Lv, X. (2019b). An approach for pulmonary vascular extraction from chest CT images. J. Healthc. Eng. 2019:9712970. doi: 10.1155/2019/9712970

Tarnanas, I., Laskaris, N., Tsolaki, M., Muri, R., Nef, T., and Mosimann, U. P. (2015). On the comparison of a novel serious game and electroencephalography 
biomarkers for early dementia screening. Adv. Exp. Med. Biol. 821, 63-77. doi: 10.1007/978-3-319-08939-3_11

Tarnanas, I., Tsolaki, M., Nef, T., Müri, R. M., and Mosimann, U. P. (2014a). Can a novel computerized cognitive screening test provide additional information for early detection of Alzheimer disease? Alzheimers Dement. 10, 790-798. doi: 10.1016/j.jalz.2014.01.002

Tarnanas, I., Tsolakis, A., and Tsolaki, M. (2014b). "Assessing virtual reality environments as cognitive stimulation method for patients with MCI," in Technologies of Inclusive Well-Being. Studies in Computational Intelligence, eds A. Brooks, S. Brahnam, and L. Jain (Berlin, Heidelberg: Springer), 39-74.

Weniger, G., Ruhleder, M., Lange, C., Wolf, S., and Irle, E. (2011). Egocentric and allocentric memory as assessed by virtual reality in individuals with amnesic mild cognitive impairment. Neuropsychologia 49, 518-527. doi: 10.1016/j. neuropsychologia.2010.12.031
White, P. J., and Moussavi, Z. (2016). Neurocognitive treatment for a patient with Alzheimer's disease using a virtual reality navigational environment. J. Exp. Neurosci. 10, 129-135. doi: 10.4137/JEN.S40827

Conflict of Interest: The authors declare that the research was conducted in the absence of any commercial or financial relationships that could be construed as a potential conflict of interest.

Copyright (c) 2019 Liu, Tan, Chen, Liu, Yang and Zhang. This is an open-access article distributed under the terms of the Creative Commons Attribution License (CC BY). The use, distribution or reproduction in other forums is permitted, provided the original author(s) and the copyright owner(s) are credited and that the original publication in this journal is cited, in accordance with accepted academic practice. No use, distribution or reproduction is permitted which does not comply with these terms. 